\title{
Biological and Molecular Characterization of a U.S. Isolate of Hosta virus X
}

\author{
Carola M. De La Torre, Feng Qu, Margaret G. Redinbaugh, and Dennis J. Lewandowski
}

First and fourth authors: Department of Plant Pathology, The Ohio State University, Columbus 43210; second author: Department of Plant Pathology, Ohio Agricultural Research and Development Center, Wooster 44691; and third author: U.S. Department of AgricultureAgricultural Research Service, Corn and Soybean Research, Wooster, OH 44691.

Accepted for publication 3 July 2012.

\begin{abstract}
De La Torre, C. M., Qu, F., Redinbaugh, M. G., and Lewandowski, D. J. 2012. Biological and molecular characterization of a U.S. isolate of Hosta virus $X$. Phytopathology 102:1176-1181.

Hosta virus $X(\mathrm{HVX})$ is rapidly becoming a serious pathogen of commercially important hosta plants worldwide. We report here biological and molecular characterization of a U.S. isolate of HVX, HVX-37. HVX37 infectivity was tested in 21 hosta cultivars over three growth seasons, and three types of responses were defined based upon the ability of the virus to cause local and/or systemic infections. Four cultivars resistant to

systemic HVX infection were identified. The full-length sequence of the HVX-37 genome was determined, the first complete sequence of a U.S. HVX isolate. Comparison with the previously sequenced HVX-Korea $(\mathrm{Kr})$ genome revealed a high level of sequence similarity, as well as some differences. Notably, a 105-nucleotide long, near-perfect direct repeat in the $\mathrm{Kr}$ isolate is absent in HVX-37. The accuracy of the HVX-37 genome sequence was confirmed by infectivity of in vitro transcripts synthesized from a full-length HVX-37 cDNA on Nicotiana benthamiana and hosta plants.
\end{abstract}

Hosta species are among the most popular garden plants and generate over \$59 million annual sales for the U.S. horticulture industry (http://www.agcensus.usda.gov). Among hosta viral diseases, Hosta virus $X$ (HVX) has caused the largest economic impact in the United States. It was first identified in local nurseries in Minnesota (13), but has since quickly spread to more than 10 states throughout the United States. HVX is transmitted by contaminated cutting tools and vegetative propagation (3) and is also seed transmitted (18). The host range of HVX is restricted to various hosta species and Nicotiana benthamiana under experimental conditions (3). HVX symptoms in hostas include leaf mosaic, leaf twisting, plant stunting, and death $(3,11,17)$.

Although HVX infestations have been widely reported in the United States, complete genome information is not available for any U.S. isolate of HVX. The sequence of HVX-Korea $(\mathrm{Kr})$, the first fully sequenced HVX genome, indicated that HVX belongs to the genus Potexvirus of the family Flexiviridae, with a singlepositive-stranded (+) RNA genome of 6,528 nucleotides (nts), encoding five open reading frames (ORFs). The $5^{\prime}$-proximal ORF encodes a putative replicase of 1,508 amino acids (aa) with a predicted molecular mass of ca. 167 kilodalton $(\mathrm{kDa})$. Three overlapping ORFs in the middle of the genomic RNA encode 26, 13, and $8 \mathrm{kDa}$ proteins that share sequence identity with the triple gene block (TGB) proteins of other potexviruses. The 3'-proximal ORF encodes the $23 \mathrm{kDa}$ capsid protein (14).

In this study, we have characterized the full-length sequence of U.S. isolate HVX-37. The sequence has high levels of sequence similarity with the $\mathrm{Kr}$ isolate, but also has notable differences. We constructed a full-length cDNA of the HVX-37 isolate, in vitro

Corresponding author: C. M. De La Torre;

E-mail address: de-la-torre-cuba.1@ buckeyemail.osu.edu

* The $\boldsymbol{e}$-Xtra logo stands for "electronic extra" and indicates that the online version contains one supplemental figure and two supplemental tables.

http://dx.doi.org/10.1094/PHYTO-02-12-0025-R

(C) 2012 The American Phytopathological Society transcripts of which were tested for their ability to produce HVX infection in hosta and $N$. benthamiana. Furthermore, the responses of 21 hosta cultivars to inoculation with HVX-37 were tested. The marked differences in responses among varieties indicated that the screening approach used provides a valuable tool for the identification of hosta varieties that are tolerant or resistant to HVX, contributing to the management of this disease.

\section{MATERIALS AND METHODS}

Virus source. The HVX isolate (HVX-37) used in this study was obtained from a symptomatic cultivar Sum and Substance plant submitted to the C. Wayne Ellett Plant and Pest Diagnostic Clinic, Department of Plant Pathology, The Ohio State University, in 2006. This plant tested positive for HVX by double antibody sandwich enzyme-linked immunosorbent assay (DAS-ELISA) using a commercially available reagent set (Agdia, Inc., Elkhart, IN). The source plant of this isolate was maintained in a greenhouse in Columbus, $\mathrm{OH}$, throughout this study.

Assessment of HVX infectivity in hosta cultivars. We selected 21 hosta cultivars (Table 1) with different morphological characteristics including leaf color (blue, green, or yellow), leaf pattern (presence or absence of white margins), and size (small, medium, or large) for testing. Except for Hosta montana and H. sieboldiana, two species originating from Japan, the tested hostas were hybrids. The hybrids were descendents of tissue culture lines derived from virus-indexed mother plants acquired in June 2007 from Q and Z Nursery, Inc. (Rochelle, IL). Plants were transplanted to 5.5 inch pots of Metro-Mix 360 (Sun Gro Horticulture, Bellevue, WA) and maintained in the greenhouse for 2 weeks until the roots were well developed. Two to seven plants of each of the 21 different cultivars were rub-inoculated on the two youngest expanded leaves with an extract of HVX-37-infected cultivar Sum and Substance plants, prepared by grinding leaves in an inoculation buffer containing $10 \mathrm{mM}$ sodium phosphate, $\mathrm{pH}$ 7.2, and $1 \%$ Celite. The inoculated plants were maintained in the greenhouse throughout the study. Plants of hosta cultivars Patriot 
and Sum and Substance were used as susceptible controls. Plants were observed for symptom development in inoculated and upper uninoculated systemic leaves. The presence of HVX coat protein (CP) in inoculated and systemic leaves was evaluated at 28 and 56 days postinoculation pi, respectively, by DAS-ELISA. Leaf samples consisted of two half leaves corresponding to two inoculated or upper young leaves. Plants were maintained in the greenhouse during the winter, and all surviving plants were re-examined the following year (2008). In spring 2008, roots were evaluated in addition to leaves. Root samples consisted of a pool of two secondary roots of the same plant. In spring 2009, leaves and roots of all cultivars that tested negative in 2008 were retested by DAS-ELISA. Samples that tested negative repeatedly by DASELISA were re-evaluated in spring 2009 by immunocapture reverse-transcription polymerase chain reaction (IC-RT-PCR). Briefly, $500 \mu \mathrm{l}$ of leaf extract, prepared by grinding $0.5 \mathrm{~g}$ leaf tissue in $5 \mathrm{ml} \mathrm{PBS}-\mathrm{S}$ buffer $\left(116 \mathrm{mM} \mathrm{Na} 2 \mathrm{HPO}_{4}, 34 \mathrm{mM} \mathrm{NaH} \mathrm{PO}_{4}\right.$, $5 \%$ sucrose, $\mathrm{pH} 7.4$ ), was transferred to a tube containing $20 \mu \mathrm{l}$ of magnetic beads (kindly provided by J. Rob Fisher, Ohio Department of Agriculture) conjugated with anti-HVX antibodies and incubated at room temperature for $2 \mathrm{~h}$ with gentle agitation. The beads were washed three times with $1 \mathrm{ml}$ of PBS-S buffer. After $1 \mathrm{~h}$ incubation in water bath at $42^{\circ} \mathrm{C}$, the beads were used to carry out reverse transcription using Moloney Murine Leukemia VirusReverse Transcriptase (Promega, Madison, WI) according to the manufacturer's recommendations. An aliquot of the resulting cDNA $(2 \mu \mathrm{l})$ was then used as template in a PCR reaction that contained primers designed to amplify a portion of the HVX replicase coding region (H16Fwd and H17Rev; Supplemental Table 1). PCR was carried out using Taq DNA Polymerase (Promega, Madison, WI) according to the manufacturer's recommendations. The cycling conditions were: one cycle of $95^{\circ} \mathrm{C}$ for $2 \mathrm{~min}$, followed by 30 cycles of $95^{\circ} \mathrm{C}, 30 \mathrm{~s} ; 50^{\circ} \mathrm{C}, 30 \mathrm{~s} ; 72^{\circ} \mathrm{C}$, $1 \mathrm{~min}$; and a final, $5 \mathrm{~min}$ extension step at $72^{\circ} \mathrm{C}$. PCR products were analyzed on a $1 \%$ agarose, $1 \times$ TAE (40 mM Tris/acetate, 1 mM EDTA, pH 8.0) gel.
Construction of a full-length cDNA clone of Hosta virus $X$. Total RNA was isolated from leaf tissue of an $H$. 'Sum and Substance' plant infected with HVX-37 using the RNeasy Plant Mini Kit (Qiagen, Valencia, CA), following the manufacturer's instructions. In independent reactions, first strand cDNA synthesis was primed with primers complementary to the $3^{\prime}$-UTR (H3Rev) or replicase sequences (H15Rev) of HVX. A 2.7-kb 5'-proximal fragment was then PCR-amplified using Pfu DNA polymerase (Promega, Madison, WI) from H15Rev-primed cDNA using primers H8Fwd and H15Rev. The sequence of the T7 promoter was added to the $5^{\prime}$-end of the $2.7-\mathrm{kb}$ cDNA fragment by PCR amplification using primers HT7PromFwd and H15Rev. A 3.7-kb 3'-proximal fragment was amplified by PCR from H3Rev-primed cDNA using primers H7Fwd and H3Rev. A poly $\left(\mathrm{A}_{25}\right)$ tail, fused to $S b f$ I and BamHI sites, was introduced at the $3^{\prime}$ terminus of the cDNA by PCR-amplification with the primers H7Fwd and HPoly(A)Rev. The 2.7- and 3.7-kb fragments, which overlap by 132 base pairs (bp), were mixed and amplified to generate the full-length cDNA of HVX-37 using long fusion PCR (19). The full-length cDNA was gel purified, digested with KpnI and BamHI, and ligated into a similarly digested pNEB193 vector. The sequence of the inserted DNA in each of five recombinant plasmids (pHVX-1 to 5) was confirmed by restriction analysis prior to using the plasmid as the template for producing HVX RNA through in vitro transcription.

In vitro transcription and infectivity assays. In vitro RNA transcripts from clones No. 1 to 5 (derived from plasmids pHVX1 to 5 , respectively) were produced with $\mathrm{T} 7 \mathrm{RNA}$ polymerase from $1.2 \mu \mathrm{g}$ of BamHI-linearized $\mathrm{pHVX}$ as previously described (12), and rub-inoculated onto $N$. benthamiana and hosta leaves dusted with silicon carbide 400 mesh (Sigma-Aldrich, Inc., St. Louis, MO). Plants were maintained in a growth chamber at $25^{\circ} \mathrm{C}$ with a $14 \mathrm{~h}$ photoperiod. Inoculated leaves of $N$. benthamiana and hosta plants were sampled at 10 and 30 days postinoculation (dpi), respectively, and tested for the presence of HVX by DASELISA and immunocapture reverse transcription-polymerase

TABLE 1. Evaluation of hosta cultivars susceptibility to Hosta virus X (HVX) using double antibody-enzyme linked immunosorbent assay (DAS-ELISA) and symptomatology

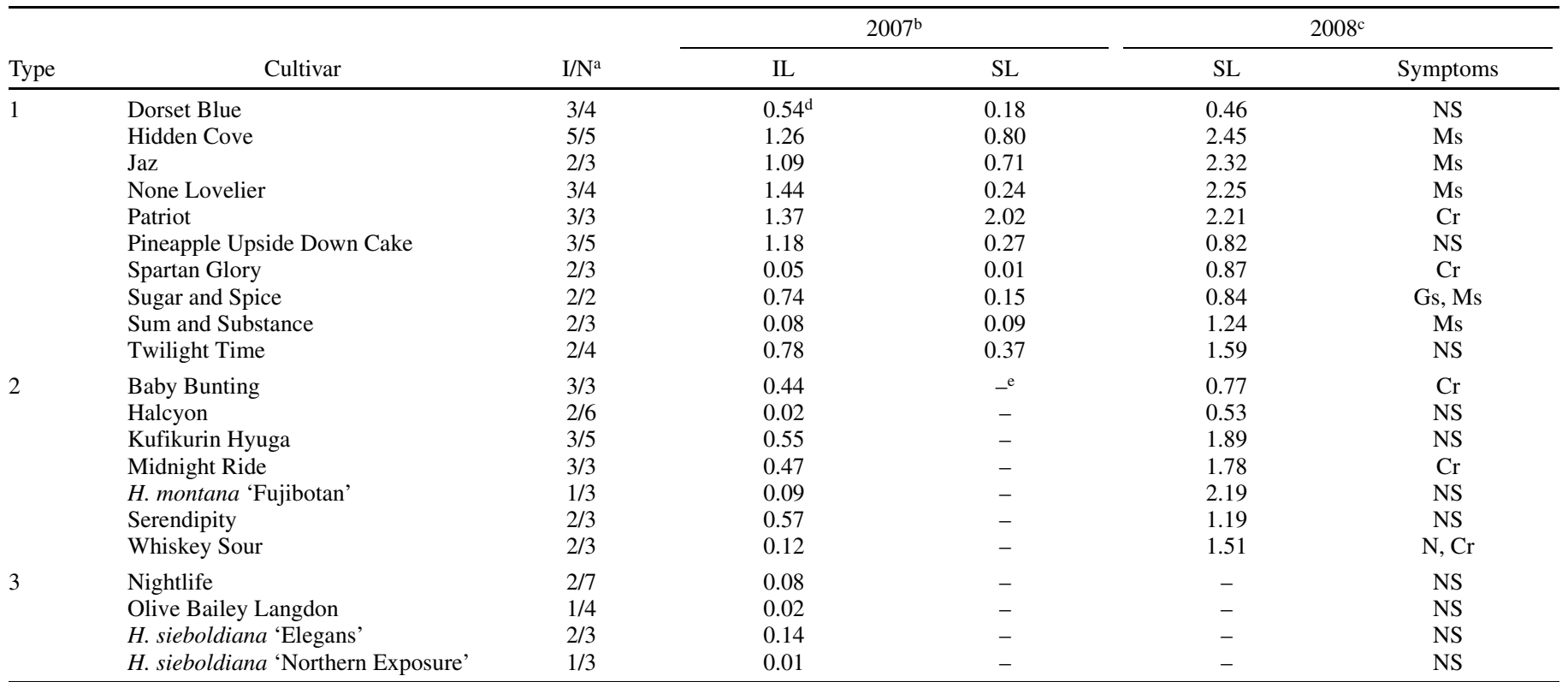

\footnotetext{
a Number of plants locally infected plants/number of plants evaluated. Note that type 3 plants did not become systemically infected.

${ }^{\mathrm{b}}$ No symptoms were observed in 2007. IL: inoculated leaves. SL: systemic leaves.

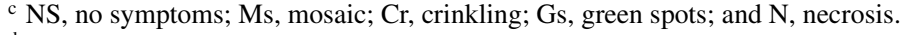

${ }^{\mathrm{d}}$ Mean average of double antibody sandwich enzyme-linked immunosorbent assay (DAS-ELISA) optical density value at $405 \mathrm{~nm}\left(\mathrm{OD}_{405}\right)$ of three plants. Values have been corrected by subtracting twice the average of $\mathrm{OD}_{405}$ background value. Numbers reflect positive values.

${ }^{\text {e }} \mathrm{HVX}$ negative test, DAS-ELISA $\mathrm{OD}_{405}<0$ after subtracting twice $\mathrm{OD}_{405}$ background value (mock-inoculated plant). $\mathrm{OD}_{405}$ average background values were 0.069 (for inoculated leaves in 2007), 0.066 (for upper noninoculated leaves in 2007), and 0.079 in 2008.
} 
chain reaction (IC-RT-PCR) as described earlier. Transcripts infectious to hosta were inoculated onto 22 additional hosta plants (four cultivars) and assayed for HVX infectivity at $30 \mathrm{dpi}$.

Transmission electron microscopy. Fresh, symptomatic leaves of a transcript-inoculated hosta cultivar None Lovelier plant were dissected with a sterile scalpel and fine sections of leaf blade were placed on a drop of $0.1 \mathrm{M}$ phosphate buffer for $1 \mathrm{~min}$. A carboncoated copper grid was then floated on the drop for $1 \mathrm{~min}$ and dried. The grid was washed four times in drops of water $(30 \mathrm{~s}$ each), placed on a drop of $1 \%$ phosphotungstic acid stain for $30 \mathrm{~s}$, and then blot-dried for $30 \mathrm{~min}$. Grids were examined using a Hitachi H-7500 transmission electron microscope (Hitachi High Technologies America, Inc.) at the Molecular and Cellular Imaging Center, OARDC, Wooster, $\mathrm{OH}$.

Sequencing of the full-length cDNA clone and HVX-37. Genome sequences from cDNA clone No. 5 and HVX-37 were obtained using a 3730 DNA analyzer (Applied Biosystems Inc., Carlsbad, CA) at The Ohio State University Plant-Microbe Genomics Facility (OSU-PMGF) and 37 primers were designed based upon the HVX-Kr genome (AJ620114). Sequences from both genomes were assembled using Seqman 5.0 (DNASTAR Inc., Madison, WI). ORFs were predicted using EditSeq (DNASTAR Inc.). The deduced protein sequence of each putative ORF was used to search for sequence similarity using BLAST (1), and ORF-encoded protein sequences with homology to other potexvirus proteins were selected for further analysis. The deduced protein products were aligned and compared with ORFs of HVX$\mathrm{Kr}$ (AJ620114) using Geneious Pro 4.7.6 (Biomatters Ltd., Auckland, New Zealand). Complete genomic sequence for the infectious full-length cDNA clone (No. 5) is available as GenBank accession no. JQ911698.

Phylogenetic analysis of HVX replicases. The deduced HVX37 and $\mathrm{HVX}-\mathrm{Kr}$ replicase protein sequences were aligned with those of 23 recognized and eight tentative potexvirus species using the MUSCLE alignment function of Geneious Pro 4.7.6 (Biomatters Ltd.). A phylogeny based on replicase sequences was inferred using the neighbor-joining method with the JTT matrix (10) and 1,000 bootstrap replicates using Mega 4.0 (21).

\section{RESULTS}

Identification of HVX-resistant hosta cultivars. To determine whether hosta varieties resistant to HVX could be identified among commonly available cultivars, we screened virus-indexed plants of 21 hosta cultivars obtained from commercial nurseries for their susceptibility to HVX-37. This study was conducted in a greenhouse over a 24-month period, spanning three growth seasons. Plants were inoculated in June 2007 and analyzed throughout 2007, 2008, and 2009. In 2007, local and systemic infections were evaluated by examining the inoculated leaves (ILs) and leaves emerging after inoculation (systemic leaves or
SLs) (Table 1). HVX was detected by DAS-ELISA in ILs of all cultivars but not in uninoculated control plants of the same cultivars (data not shown). However, only 10 of the 21 cultivars became systemically infected by $56 \mathrm{dpi}$. No obvious symptoms were observed in 2007 on any of the plants, including those that tested positive for systemic HVX infection by DAS-ELISA at 56 dpi.

In 2008, SLs of all plants were retested by DAS-ELISA. The 10 cultivars that were systemically infected with HVX in 2007 remained infected in 2008. Seven of the eleven cultivars for which virus was detected only in ILs at 56 dpi in 2007 were systemically infected by 2008 (Table 1). However, newly emerging leaves of hosta 'Olive Bailey Langdon', 'Nightlife', H. sieboldiana 'Elegans', and $H$. sieboldiana 'Northern Exposure' tested negative for HVX. Based on these results, the tested cultivars were grouped into three types depending on the pattern of HVX infection: type 1, systemic infection in both 2007 and 2008; type 2, systemic infection delayed until 2008; type 3, localized infection detected only in 2007 (Table 1).

In 2009, the type 3 cultivars were reexamined to determine if delayed systemic infections had developed in any of these cultivars. Leaves and roots were sampled from two to seven plants of each of the four cultivars, and none of the samples was positive for HVX using DAS-ELISA. Similarly, no products were detected using IC-RT-PCR from leaf tissue (data not shown). Conversely, HVX was consistently detected by IC-RT-PCR from both leaves and roots of our positive control plant ('Midnight Ride'), indicating that hosta 'Nightlife', $H$. sieboldiana 'Elegans', $H$. sieboldiana 'Northern Exposure', and hosta 'Olive Bailey Langdon' are resistant to systemic spread of HVX.

Generation of an infectious cDNA clone of HVX-37. A fulllength cDNA of HVX-37 was generated by RT-PCR and cloned into pNEB193 downstream of the T7 promoter. Five clones containing inserts of the expected size for HVX were used to generate in vitro transcripts for plant inoculation. Since HVX was known to infect $N$. benthamiana (albeit often asymptomatically), we used $N$. benthamiana plants to test the infectivity of in vitro transcripts of HVX cDNA clones. All five clones produced transcripts that resulted in infection of some, but not all, inoculated $N$. benthamiana plants as determined by DAS-ELISA and IC-RTPCR (Table 2). Transcripts synthesized from clones No. 2, 3, and 5 were also inoculated to leaves of four different hosta cultivars ('Midnight Ride', 'None Lovelier', 'Sugar and Spice', and 'June'). The identity of HVX in the infected plants was confirmed by four different methods: IC-RT-PCR, DAS-ELISA, symptom evaluation, and transmission electron microscopy. The infectivity of the transcripts was relatively low in hosta, as transcripts from clones No. 2 and 5 caused infection in only one and two plants, respectively, of the 15 inoculated hosta plants based on the IC-RTPCR and DAS-ELISA results (Table 2). The transcript-infected hostas showed mild HVX symptoms during the second growing

TABLE 2. Infectivity assessment of in vitro transcripts derived from full-length Hosta virus $X$ (HVX) cDNA

\begin{tabular}{|c|c|c|c|c|c|c|c|}
\hline \multirow[b]{2}{*}{ Inoculated plant } & \multicolumn{5}{|c|}{ HVX clone $^{\mathrm{a}}$} & \multirow[b]{2}{*}{ Mock $^{\mathrm{b}}$} & \multirow[b]{2}{*}{ Sap $^{c}$} \\
\hline & 1 & 2 & 3 & 4 & 5 & & \\
\hline Nicotiana benthamiana & $1 / 5^{\mathrm{d}}$ & $2 / 5$ & $3 / 5$ & $1 / 5$ & $3 / 5$ & $0 / 5$ & $5 / 5$ \\
\hline Hosta 'June' & $n t^{e}$ & $1 / 4$ & $0 / 4$ & nt & $0 / 4$ & $0 / 4$ & $4 / 4$ \\
\hline Hosta 'None Lovelier' & $\mathrm{nt}$ & $0 / 3$ & $0 / 3$ & $\mathrm{nt}$ & $1 / 3$ & $0 / 3$ & $3 / 3$ \\
\hline Hosta 'Sugar and Spice' & nt & $0 / 4$ & $0 / 4$ & $\mathrm{nt}$ & $1 / 4$ & $0 / 4$ & $4 / 4$ \\
\hline
\end{tabular}

${ }^{a}$ HVX clone used to produce RNA transcripts in vitro.

b Mock = buffer-inoculated plant.

c Sap = plant inoculated with leaf extract from a HVX-37-infected hosta.

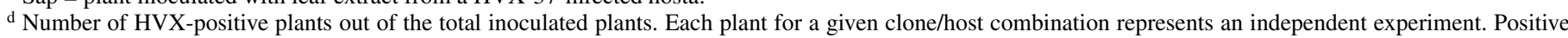
plants are based on immunocapture reverse-transcription polymerase chain reaction and double antibody sandwich enzyme-linked immunosorbent assay (DASELISA) results. In DAS-ELISA, absorbance values $\left(\mathrm{A}_{405}\right)$ over twofold the value of mock-inoculated plants were considered positive.

e nt, not tested. HVX-2, HVX-3, and HVX-5 were positive in $N$. benthamiana during the first three experiments and were selected for inoculation into hosta. 
season (Supplemental Figure 1). Electron microscopy examination of leaves from transcript-infected hostas showed filamentous virions of ca. $540 \mathrm{~nm}$ long and ca. $13 \mathrm{~nm}$ diameter.

Although the infectivity of in vitro-transcribed RNAs was low, the sap from a DAS-ELISA positive 'None Lovelier' plant caused infection in single-plant inoculation of 'Halcyon', 'Francee', 'Midnight Ride', 'Patriot', 'Northern exposure', 'Spartan Glory', 'Baby Bunting', H. montana 'Fujibotan', 'Whiskey Sour', and 'None Lovelier' as determined by DAS-ELISA at 30 dpi (data not shown).

Genome sequence comparison between HVX-37 and HVXKr. The viral consensus genome sequence (HVX-37 and clone No. 5) resulted in the assembly of a 6,431-nt contig compared with 6,528 nts for HVX-Kr (AJ620114). HVX-37 and clone No. 5 sequences were nearly identical with only two synonymous substitutions. The HVX-37 genome (Fig. 1A) has a 104-nt 5'UTR and a 108-nt $3^{\prime}$-UTR [excluding the poly(A) tail], and contains five ORFs encoding proteins with homology to the potexvirus replicase, TGBp1, TGBp2, TGBp3, and CP. Comparison of the HVX-37 genome sequence with $\mathrm{HVX}-\mathrm{Kr}$ revealed a high degree of sequence homology, but notable differences as well (Supplemental Table 2). The viral replicase encoded by the $5^{\prime}$ proximal HVX-37 ORF is 1,473 aa long, 35 aa shorter than HVX$\mathrm{Kr}$. This is due to the presence of a $105 \mathrm{nt}$ near-perfect direct repeat in the HVX-Kr sequence, but not in that of HVX-37 (Fig. 1B). Multiple gaps in the alignment of the HVX-37 and $\mathrm{HVX}-\mathrm{Kr}$ replicases cDNA sequences resulted in frame shifts and multiple amino acid sequence differences between the two replicase proteins (Fig. 1B). Most gaps were located in the variable region between the methyltransferase and helicase motifs. Elsewhere in the genome, there were relatively few amino acid differences in TGBp1 and TGBp2 sequences. The TGBp3 ORF has a nonconventional start codon (UUG) in HVX-37, but not HVX-Kr. The deduced amino acid sequences for CP of the two HVX isolates were identical.

HVX replicase protein sequence comparison with other potexviruses. To determine the relationship between HVX and other potexviruses, we aligned the HVX-37 sequence with 31 potexviral replicases available in GenBank. In pairwise comparisons, the HVX-37 replicase was more similar to the other potexvirus replicases evaluated than the HVX-Kr replicase. In general, the potexvirus replicase sequences showed the highest level of similarity within the methyltransferase, helicase, and RNAdependent RNA polymerase domains and the lowest level of similarity in the region between the methyltransferase and heli-

A

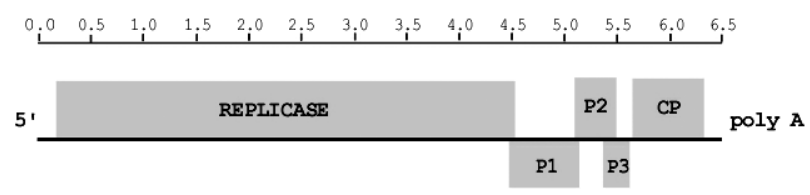

B

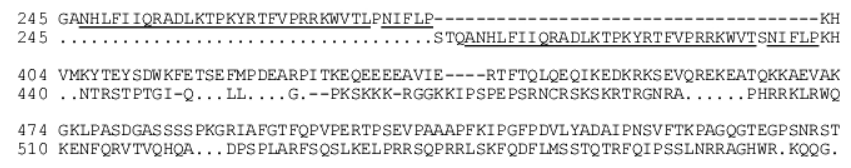

Fig. 1. Genome organization of Hosta virus $X$ (HVX) isolate, HVX-37. A, Proposed HVX genome organization showing putative genes: replicase, TGBp1(p1), TGBp2 (p2), TGBp3 (p3), coat protein (CP); 5' and $3^{\prime}$ untranslated region. B, Pairwise alignment between HVX-37 (top) and HVX$\mathrm{Kr}$ (bottom) replicase sequences showing a nearly identical repeat (underlined letters) in HVX-Kr that is absent in HVX-37. Sequence comparison also showed a replicase region of low similarity between amino acid positions 404 and 548 of HVX-37. Only amino acids that differ from HVX-37 are shown; periods indicate identity and dashes represent gaps inserted for alignment.
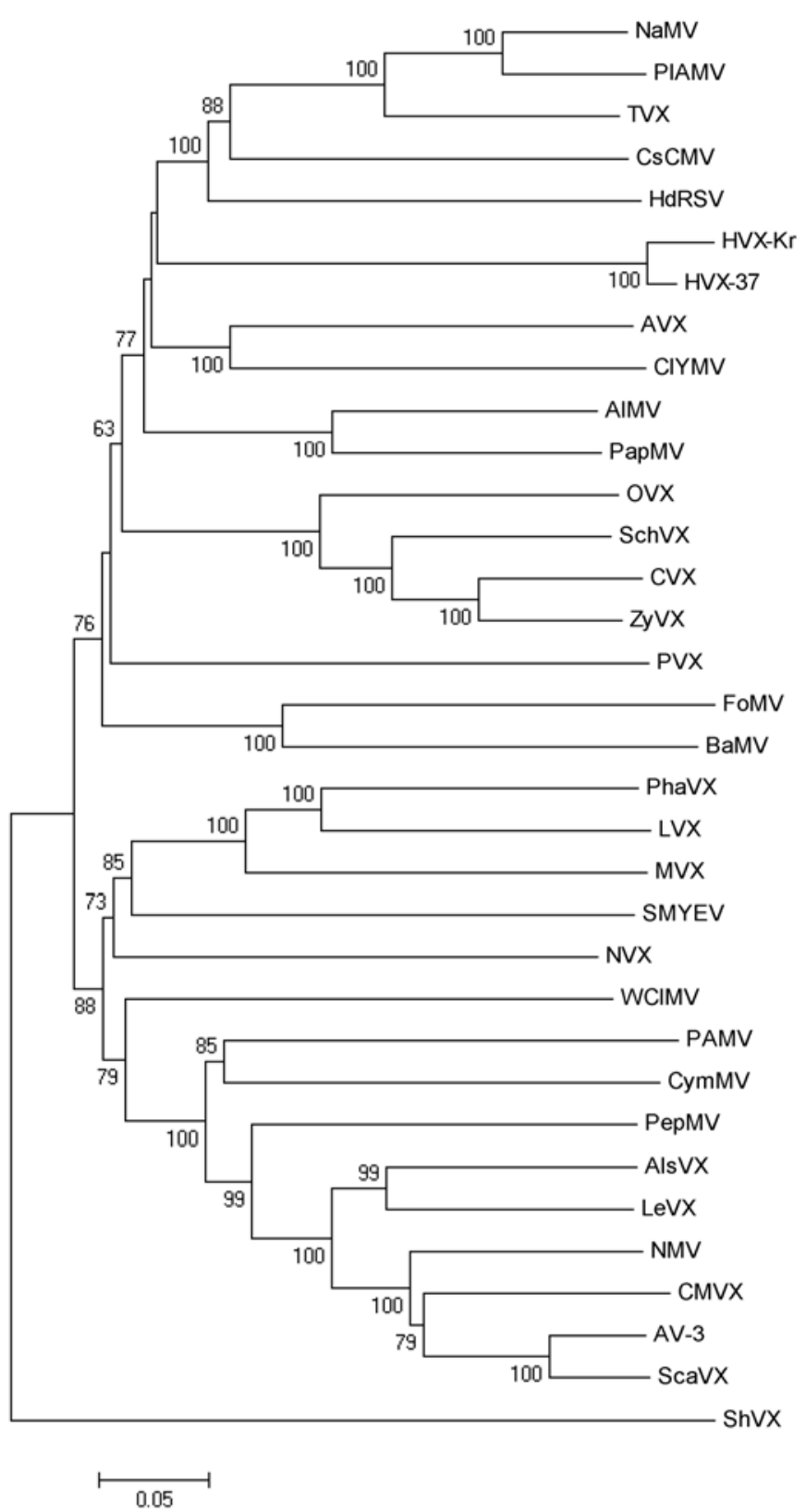

Fig. 2. Phylogenetic tree of the replicase amino acid sequence of 31 potexvirus species constructed by neighbor-joining method, 1,000 bootstrap replicates, 93,776 seeds, complete deletion of gaps, p-distance model. Hosta virus $X$ isolate HVX-37, Hosta virus $X$ isolate HVX-Kr, YP_002308464; Bamboo mosaic virus (BaMV), NP_042582; Potato virus X (PVX) CAA80774; Alstroemeria virus $X$ (AlsVX), YP_319827; Foxtail mosaic virus (FoMV), NP_040988; Opuntia virus X (OVX), YP_054407; Schlumbergera virus $X$ (SchVX), YP_002341559; Cactus virus X (CVX), NP_148778; Zygocactus virus X (ZyVX), YP_054402; Allium virus X (AVX), YP_002647027; Clover yellow mosaic virus (ClYMV), NP_077079; Alternanthera mosaic virus (AltMV), ACS28233; Papaya mosaic virus (PapMV), NP_044330; Hydrangea ringspot virus (HdRSV), YP_224084; Cassava common mosaic virus (CsCMV), NP_042695; Tulip virus X (TVX), NP_702988; Plantago asiatica mosaic virus (PlAMV) NP_620836; Nandina mosaic virus (NaMV), AAX19931 (PlAMV strain); Strawberry mild yellow edge virus (SMYEV), NP_620642; Potato aucuba mosaic virus (PAMV), NP_619745; Cymbidium mosaic virus (CymMV), NP_054025; Pepino mosaic virus (PepMV), ACJ74161; Lettuce virus X (LeVX), YP_001960940; Narcissus mosaic virus (NMV), AAP51012; Chenopodium mosaic virus X (CMVX), YP_667844; Scallium virus $X$ (ScaVX), NP_570726; Asparagus virus 3 (AV-3), YP_001715612; Mint virus X (MVX), YP_224134; Phaius virus X (PhaVX), YP_001655010; Lillium virus X (LVX), YP_263303; White clover mosaic virus (WCIMV), NP_620715; Nerine virus X (NVX), YP_446992; and Shallot virus $X$ (ShVX), NP_620648 (outgroup). 
case domains. A phylogenetic tree based upon the multiple alignment of potexviral replicase protein sequences indicates that the HVX replicase is most closely related to Tulip virus $X$ (TVX), Plantago asiatica mosaic virus (PlAMV), Hydrangea ringspot virus (HdRSV), and Cassava common mosaic virus (CsCMV) (Fig. 2).

\section{DISCUSSION}

Differential responses of hosta cultivars to HVX. We assessed the responses of 21 Hosta cultivars to inoculation with an Ohio isolate of HVX. The responses could be divided into three types. Type 1 contained cultivars that were fully susceptible to HVX, including Patriot and Sum and Substance, which were previously shown to be susceptible (2). Plants in this group tested positive for HVX in ILs within 28 dpi and in SLs within 56 dpi, indicating that they readily support HVX replication and systemic spread. In the type 2 response, low levels of infection in ILs were observed, in which HVX was not detected up to 56 dpi in the first year. In these cultivars, HVX was detected in SL in the second year of evaluation. In the type 3 response, HVX was detected only in ILs, and was not detected in SLs over the 3-year evaluation period. These results suggest that type 3 cultivars are resistant to systemic infection by HVX. It has been previously reported that reduced cell-to-cell movement and/or failure to infect certain cell types can limit viral entry into the vascular system, thus resulting in resistance at the whole plant level (4). The results are consistent with those of Blanchette and Lockhart (2), who found HVX-inoculated $H$. sieboldiana 'Elegans' plants never became systemically infected during a 3 -year period.

The rationale for a multiyear assessment of various hosta cultivars was based on the observation made by Blanchette and Lockhart (2), who found that it was necessary to evaluate hosta cultivars over more than one growing season to determine if a cultivar can become systemically infected with HVX. By monitoring cultivar responses over three seasons, more subtle differences in the responses of cultivars to HVX inoculation could be detected, allowing us to distinguish between cultivars that became systemically infected within 56 dpi (Type 1) and those in which systemic infection took longer to occur (Type 2).

The cultivars identified as having a type 3 response offer the greatest potential as sources of resistance for breeding programs. All four of the type 3 cultivars have a common genetic background that includes $H$. sieboldiana 'Elegans'. Cultivars Northern Exposure and Olive Bailey Langdon are sports of $H$. sieboldiana 'Elegans', whereas 'Nightlife' is a hybrid between $H$. sieboldiana 'Elegans', and 'Invincible'. This suggests that the inability of HVX to infect SLs is a genetically heritable trait and that $H$. sieboldiana may be the source of resistance to HVX. Furthermore, the heterozygous state of type 3 cultivar plants suggests that this type of resistance is associated with a dominant gene. $\mathrm{H}$. sieboldiana 'Elegans' is a favorite cultivar for hybridization because of its ornamental features (24) and may be crossed with susceptible Hosta species and cultivars for further studies on the mode of resistance inheritance.

Molecular characterization of HVX. Transcripts from fulllength HVX cDNA clones were infectious to hosta and N. benthamiana as demonstrated by DAS-ELISA, IC-RT-PCR, transmission electron microscopy, and symptom evaluation. Higher rates of infection were observed in $N$. benthamiana plants, possibly due to a thinner cuticle than hostas. RNA inoculation difficulties have been documented for other crops with a thick cuticle. For example, in vitro transcripts of Citrus leaf blotch virus yielded no infected citrus but were fully infectious in $N$. benthamiana protoplasts (22).

The genomic sequence of HVX-37 was determined and compared with that of a Korean isolate (HVX-Kr), as well as those of other potexviruses. The HVX-37 genome sequence had high similarity with HVX-Kr in each of the ORFs except for the replicase. Comparison between the HVX-37 and HVX-Kr replicase proteins identified differences in two usually highly conserved areas. Relative to HVX-37, the HVX-Kr cDNA sequence has a duplicated region within the methyltransferase domain of HVX$\mathrm{Kr}$ replicase, and the deduced amino acid sequence lacks the GKS motif required for NTPase and RNA 5'-triphosphatase activities (7). Phylogenetic analysis based upon the complete replicase sequence revealed that HVX is more closely related to TVX, PlAMV, CsCMV, and HdRSV as previously shown in an analysis based on HVX TGB and CP $(5,14)$.

Although most of the proteins are highly conserved between HVX-37 and HVX-Kr, a main difference exists in the putative TGBp3 start codon. As noted above, HVX-37 contains a TGBp3 UUG start codon. Non-AUG start codons (AUU, CUG, UUG) are normally found in RNA viruses $(8,9,15,16,23)$ and are one of the mechanisms employed by viruses in noncanonical translation (6). Although UUG has been previously reported as a putative ORF start codon in Garlic virus $X$, genus Allexivirus, family Flexiviridae (20), this is the first report showing a UUG start codon in the genus Potexvirus.

In summary, we have found three types of response to HVX inoculation among hosta cultivars and identified four cultivars that are resistant to the virus. We also succeeded in producing an infectious clone of HVX-37, the first HVX infectious clone currently available, and carried out in silico analysis of HVXcoded proteins compared with other potexviruses. Our results are expected to provide a solid basis for additional in-depth investigations, as well as improved control measures of HVX-caused hosta diseases.

\section{ACKNOWLEDGMENTS}

This research was supported in part by the Ohio Agricultural Research and Development Center (OARDC) Seeds Grant Award and the Ohio Plant Biotechnology Consortium (OPBC). We thank T. Meulia (OARDC Molecular and Cellular Imaging Center) for assistance with the electron microscope and J. R. Fisher (Ohio Department of Agriculture) for providing us with magnetic beads conjugated with anti-HVX antibodies.

\section{LITERATURE CITED}

1. Altschul, S. F., Gish, W., Miller, W., Myers, E. W., and Lipman, D. J. 1990. Basic local alignment search tool. J. Mol. Biol. 215:403-410.

2. Blanchette, B., and Lockhart, B. E. L. 2003. Hosta virus X: A three-year study. Hosta J. 35:19-23.

3. Currier, S., and Lockhart, B. E. L. 1996. Characterization of a potexvirus infecting Hosta spp. Plant Dis. 80:1040-1043.

4. Dawson, W. O., and Hilf, M. E. 1992. Host-range determinants of plant viruses. Annu. Rev. Plant Physiol. Plant Mol. Biol. 43:527-555.

5. Fajolu, O. L., Wen, R. H., Windham, A. S., Windham, M. T., Moulton, J. K., and Hajimorad, M. R. 2009. Genetic variability and phylogenetic analysis of Hosta virus X. Arch. Virol. 154:1909-1916.

6. Firth, A. E., and Brierley, I. 2012. Non-canonical translation of RNA viruses. J. Gen. Virol. Online publication. doi:10.1099/vir.0.042499-0

7. Han, Y. T., Tsai, C. S., Chen, Y. C., Lin, M. K., Hsu, Y. H., and Meng, M. 2007. Mutational analysis of a helicase motif-based RNA 5'-triphosphatase/NTPase from Bamboo mosaic virus. Virology 367:41-50.

8. Jang, C. J., Lo, M. C., and Jan, E. 2009. Conserved element of the dicistrovirus IGR IRES that mimics an E-site tRNA/ribosome interaction mediates multiple functions. J. Mol. Biol. 387:42-58.

9. Jelkmann, W., Maiss, E., and Martin, R. R. 1992. The nucleotide sequence and genome organization of strawberry mild yellow edge-associated potexvirus. J. Gen. Virol. 73:475-479.

10. Jones, D. T., Taylor, W. R., and Thornton, J. M. 1992. The rapid generation of mutation data matrices from protein sequences. Comput. Appl. Biosci. 8:275-282.

11. Lewandowski, D. J. 2008. Hosta virus X. Online publication/HYG-306908. http://online.osu.edu/hyg-fact/3000/pdf/3069.pdf

12. Lewandowski, D. J., and Dawson, W. O. 1998. Deletion of internal sequences results in Tobacco mosaic virus defective RNAs that accumulate to high levels without interfering with replication of the helper virus. Virology 251:427-437. 
13. Lockhart, B. E. L., and Currier, S. 1996. Viruses occurring in Hosta spp. in the USA. Acta Hortic. 432:62-71.

14. Park, M. H., and Ryu, K. H. 2003. Molecular evidence supporting the classification of Hosta virus $X$ as a distinct species of the genus Potexvirus. Arch. Virol. 148:2039-2045.

15. Petty, I. T. D., and Jackson, A. O. 1990. Two forms of the major barley stripe mosaic virus nonstructural protein are synthesized in vivo from alternative initiation codons. Virology 177:829-832.

16. Pooggin, M. M., Fütterer, J., Skryabin, K. G., and Hohn, T. 2001. Ribosome shunt is essential for infectivity of Cauliflower mosaic virus. Proc. Natl. Acad. Sci. USA 98:886-891.

17. Ryu, K. H., Park, M. H., and Lee, J. S. 2002. Occurrence of mosaic disease of hosta plants caused by Hosta virus X. Plant Pathol. J. 18:313-316.

18. Ryu, K. H., Park, M. H., Lee, M. Y., and Lee, J. S. 2006. Characterization and seed transmission of Hosta virus $X$ isolated from hosta plants. Acta Hort. 722:91-94.
19. Shevchuk, N. A., Bryksin, A. V., Nusinovich, Y. A., Cabello, F. C., Sutherland, M., and Ladisch, S. 2004. Construction of long DNA molecules using long PCR-based fusion of several fragments simultaneously. Nucleic Acids Res. 32:e19.

20. Song, S., Song, J., Kim, C., Lee, J., and Choi, Y. 1998. Molecular characterization of the Garlic virus X genome. J. Gen. Virol. 79:155-159.

21. Tamura, K., Dudley, J., Nei, M., and Kumar, S. 2007. MEGA4: Molecular evolutionary genetics analysis (MEGA) software version 4.0. Mol. Biol. Evol. 24:1596-1599.

22. Vives, M. C., Martin, S., Ambros, S., Renovell, A., Navarro, L., Pina, J. A., Moreno, P., and Guerri, J. 2008. Development of a full-genome cDNA clone of Citrus leaf blotch virus and infection of citrus plants. Mol. Plant Pathol. 9:787-797.

23. Wilson, J. E., Pestova, T. V., Hellen, C. U., and Sarnow, P. 2000. Initiation of protein synthesis from the A site of the ribosome. Cell 102:511-520.

24. Zilis, M. R. 2009. The Hostapedia. Q\&Z Inc., Rochelle, IL. 